\title{
EduHub Portal using Star Rating System
}

\author{
Yuvraj Chaudhari \\ Computer Engineering \\ K.C.E.S's. College of \\ Engineering \& IT \\ Jalgaon, India
}

\author{
Shraddha Patil \\ Computer Engineering \\ K.C.E.S's. College of \\ Engineering \& IT \\ Jalgaon, India
}

\author{
Gaurav Wagh \\ Computer Engineering \\ K.C.E.S's College of \\ Engineering \& IT \\ Jalgaon, India
}

\author{
Harsha V. Talele \\ Computer Engineering \\ K.C.E.S's College of \\ Engineering \& IT \\ Jalgaon, India
}

\begin{abstract}
EduHub portal is a web-based application which helps end user to find any particular type of institute such as school, colleges, any private classes with searching criteria like preferred location, subject and news. The increasing searching of institutes and changing scenario of the environment today has made more people to search for better career and potential. This situation has prompted many to move to education hub portals to look for the ways that has been accepted and fully useful in institute searching. Education hub portal brings information together from diverse source in a uniform way. Updates to the members about recent changes in any information which is an additional feature. In EduHub portal latest scripting technologies like HTML, CSS, java script and PHP are used. Unique feature of review blog for posting reviews has been added. In this portal Star rating system is use by using jQuery and Ajax to user can rating any institutes by knowing its features and facilities such as infrastructure, staff members, etc. In this portal use MySQL database to store all institutes information.
\end{abstract}

\section{Keywords}

Web Portal, Database, MySQL, Educational Directory, Star Rating System

\section{INTRODUCTION}

A key feature of the ongoing growth of the Worldwide Web over the past five years has been a proliferation of web portals that focus on supporting school education. While many such sites require subscription and registration, there are large numbers that deliver services free of charge to anyone with Internet access [1]. A Web Portal is a collection of Web forms, Web pages, images, videos, text and other forms of digital assets that is hosted on one or several web servers. It is basically a Website and a part Web Application, as it would be providing services and information to users easily, regarding the latest institute news, all details such as what is about, facilities, courses, staff or team members also its infrastructure photos gallery, etc. This application provides information about the all institutes who are register and the news of given institute which are add, update by that institute. Also, in this institute can display its current, upcoming events which are organise by that institute and also this event display can access by given institute.

This Portal would be handled by an institute administration itself and also main admin who maintain this portal. With the help of this web application user can access all details of require institutes by sign up account in portal.

In this portal, user can add review about that institute which he visits that institute. Also, in this, main feature for user as he can also review by Star Rating System using MySQL. In Star Rating System rating out of five stars but in this portal arrange rating by staff of institutes, rating by its infrastructure, etc and also overall rating. Then calculate the average rating and submit it as review.

In this EduHub Portal, any institute can add their institute such as any college, any schools, any private classes in which hobby classes, sport, etc. Once any institute add their institute, then request send to main admin. Then as long as main admin verifies it unless that institute display on user interface. This is the feature of this web application.

Also, in this portal, institute who are register and verify that institute can create job vacancy advertise into their user display with their display. It means user can access all details of require institute and also its job vacancies. This Project will be developed using OPEN SOURCE technologies such XAMMP developed from WAMP (Windows Apache MySQL and PHP).

\section{LITERATURE SURVEY}

The main idea behind this work is in the coding and the layout of each and every page which ultimately decides the outcome of the web site. The Design and Accessibility of a page is related to the Front-end of the Web site, which is an experience any user will have while navigating through the web site but the Coding part of it is something the Programmer has to diligently take care of, as it will dictate the robustness and the flow of the entire website. A lot of issues arise when using various Scripting languages simultaneously to code certain part of the pages and their interoperability. Each language is powerful and unique in its own way. So, combing them to optimize the output is a challenge. Various issues such as Redundancy, Security issues, Code Optimization, effective modeling, etc. Here are some research papers which address the various issues and optimization techniques in the building and designing of a website using the various languages used to code them.

Pratibha S. Yalagi, Chaitrali S. Dangare [2], developed E-Cl!k Portal aims to layout a web portal for institutes the place all the facilities will be provided on line for quite a number of things like E-Submission, E-Alerts, E-Learning, EExamination, E-Records, E-Result, etc. This portal gives beneficial facilities for college students and faculties who desire to get right of entry to the portal at desk of one click on sitting anywhere. We are designing a net portal E-Cl!k for our institute, which will supply facilities such as submission, handouts, notice, results, records, examinations, and so on to students.

Ofoegbu E. O, Fayemiwo M. A., Omisore M. O., Olanrewaju P. O. [3], proposed and described a net portal architecture for implementation in non-public universities in Nigeria. two The waterfall mannequin used to be adopted as the methodology of desire where it prescribes a systematic approach to software program improvement which helps to truly outline each the person and system requirements, the portal proposed was once developed the usage of various development equipment such 
as WAMP applications where the Windows platform is the operating gadget on which the portal runs, Apache is the server, while MySQL was used for the database and PHP as the scripting language. A mannequin of the portal used to be designed the usage of modelling equipment such as Data Flow Diagram (which blanketed student level statistics glide diagram, lecturer level data float diagram, administrator level data float diagram) and the Use Case Diagram.

Anand Singh, Aishwary Shukla, Maulik Sharma, Rahul Yadav, Vidyadhari Singh [4], increase placement Web Portal is a system which pursuits at imparting an easy and automatic gadget for conducting placements at some point of Campus Recruitment Drive. If placement procedure is performed manually, then a lot of additional paperwork wishes to be done; it requires a lot of time. This system will eradicate all guide work, by means of automating the facts collection procedure, conduction of tests, showing of results, as properly as, storing it, notifying the eligible students via. Email and SMS, exhibiting the listing of eligible college students etc. They have been used sentimental analysis in this portal that assessment is completed automatically and a bar format is generated indicating positive, terrible and impartial ideas of the college students about the tests. Resume builder use to standardized structure will be served on the portal and college students will simply have to enter their capabilities in the respective matters and that's it. All students' facts will be available in the database. Report Generation use to analysis of Placed students, Un-placed students, department wise placement will be reachable through this tool.

Prof. Omkar. S. Vaidya, Mr. Tanmoy Bakshi [5] design and construct a Web portal for the university department. This Web portal will consist of more than a few interlinked net pages comprising of a variety of kinds of records and things to do catering to the needs of the department. Crucially, it serves to decrease the communication gap between the school and the students by way of imparting a variety of offerings and functions such as an open discussion board for discussion, sharing of category notes, event news, effects and database of journal publications as nicely as generating timetables. They aim to accomplish this the usage of the brand-new scripting applied sciences like HTML, CSS, java script and PHP.

Saurabh Walia and Satinderjit Kaur Gill have designed a Framework for Web based Student file Management in [6] exclusively for Colleges and Universities. The statistics framework is essential in gathering all records also records of all team of workers or section in one association to be in one spot. The framework is typically given extremely accommodating errand that will supplant the human as to maintain it in document as the stock or distinctive purposes. To outline a supportive framework with a specific cease, aim to make simplicity to the client, the framework is created by using utilizing Xampp Server interfacing with database that is the usage of 'PHP' language as the dialect or guideline of the framework. The proposed framework is a standalone framework. This framework cantered on recording and updating the information. It is moreover given file on the different hand printed document to the patron in the framework which will make the repute of the pupil less difficult to be checked. This new framework utilized database concept to keep all the facts which related with vicinity application forms. This framework focused round database concept which is more solid. All learner information will be kept in a dedicated database. By utilising this database idea, a few issues, for example, data misfortune and harm may want to be stayed away from. This framework moreover targeted to make a easy checking students' status. By making use of this framework, staffs can test the students' fame quicker in time contrasted with the current framework. Hence, the personnel can lessen protecting up time in place to take a look at all the files like some time recently. The different target is the difficulty that identified with looking and upgrading the information. Staffs can pursuit and upgrade the data methodically. This framework will provide a few capacities, for example, searching and overhauling so as to assist the staffs to manipulate the information applications.

\section{EXISTING SYSTEM}

Currently we have many websites (e.g. www.shikha.com, www.carrer360.com, etc) which have identical feature of offering institutes details. They provide many functions to interact users. The biggest limitation/problems with these web sites are not user pleasant and person have to end up paid member of websites and also if they favour to locate some pastimes type classes institutes then, they have to fail it. Even institutes web sites restrict to only education associated find out about no different mastering things to do is not included. But in this portal, there is no longer such restrict to user and user can easily get entry to related direction and additionally have privileges to access it. User is not only limited to view some popular institutes but it additionally consists of all kinds of small and large institutes (e.g. dancing, guitar learning, mehandi, etc.)

\section{PROPOSED SYSTEM}

Our EduHub Education Directory Project will help the any institute to transmit their details to the user. The user who want to search institute about any subject will able to get all the information regarding courses, offers, events, news, etc. Admin panel will also able to edit the login display panel of institute and user etc. Admin can add an institute, delete the institute, can give special permission. Admin can schedule classes, their events date and time. User can get information of any institute under them require filtration such as preferred location, course, etc. Admin can add their institute by selecting categories such as course, medium, etc.

For user section, they can get any particular institute's details, news, events, job vacancies such as placement session details, upcoming companies in particular month, their criteria, their venue details and many more and other information regarding their campus. The user section will also include review and blogs sections.

\section{IMPLEMENTATION}

The basic requirements for the design of the Education Directory are: Every user in this case institute should have their own identity first Registration and second Login facility called as institute admin. The institute admin can update their information and can add events, news, job vacancies. The user can access the information and avail services as per his/her need.

\subsection{User Module}

In this module, user can view all details information of needed institutes. User can add institute as a favourite. In this module, news section, different events section and job vacancy should display. User can add review in review block and rate particular institutes.

\subsection{Institute Admin Module}

In this module, an institute which want to add in this portal, they can add by registration and login. By selecting categories of institutes and filling appropriate details which are in 
registration form it will request to server to verify it. Institute admin can update their information by this module.

\subsection{Server Side}

The Server end deals with Server hosting the web pages. Since, this is a Dynamic Website; a Server should be capable of handling User requests. PHP programming language will be used to script and code the Server. In server side as long as, main admin verifies an institute after it display on user interface. Also, main admin can add, update, delete any institute.

\subsection{Database}

Since, Our Web Portal will be an interaction of User Profiles; the data of the registered Users have to be stored on a database for Application, Management and Security Purposes. MySQL is an effective tool for Database Management System (DBMS). In our database there are total twenty tables such as institute_admin, institute details, etc. In this project we categorized institute as college, school and classes.

\subsection{Form Validation}

Form validation normally used to occur at the server, after the client had entered all the necessary data and then pressed the Submit button. If the data entered by a client was incorrect or was simply missing, the server would have to send all the data back to the client and request that the form be resubmitted with correct information. This was really a lengthy process which used to put a lot of burden on the server. JavaScript provides a way to validate form's data on the client's computer before sending it to the web server. Form validation generally performs two functions.

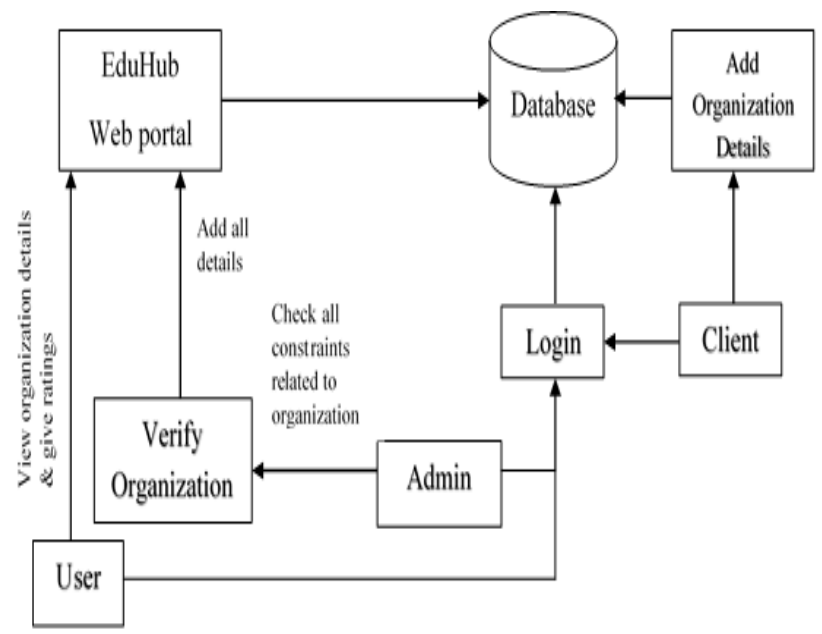

Fig 1: Block Diagram of Portal

\subsection{Star Rating System}

In this, calculate star ratings for display on Education Hub Portal. The intent is to use a simple calculation which permits quit users to visualize Institutions performance in the shape of star ratings. In general, the star ranking is clearly the suggest rating divided through 20 , to get a star rating on a $0-5$ scale. Questions observe the identical logic, but are slightly more complicated due to the different survey response scales. Due to the small range of feasible values (i.e. 0-5). In big name rating system, there is response scale conversion shown in following table.
Table I. Response Scale

\begin{tabular}{|c|c|c|c|c|c|}
\hline & $\begin{array}{c}\text { Very } \\
\text { Poor }\end{array}$ & Poor & Fair & Good & $\begin{array}{c}\text { Very } \\
\text { Good }\end{array}$ \\
\hline Score & 0 & 25 & 50 & 75 & 100 \\
\hline
\end{tabular}

Consider some questions will be arise for rating such as:

1. Administrative System.

2. Faculty Qualifications.

3. Institutional Features.

4. Students' characteristics were set in the questionnaire, which revealed the quality of current education.

5. Name of University.

Above questions have several response scales. For the purpose of calculating star ratings, we use the following conversions in order to calculate scores on a 0-100 scale:

Table II. Star rating Scale

\begin{tabular}{|c|c|c|}
\hline & No* & Yes* \\
\hline Score & 0 & 100 \\
\hline
\end{tabular}

The conversion of yes/no items depends on which response is the most favorable option.

To illustrate this calculation, consider the example below:

Table III. Example of star rating

\begin{tabular}{|c|c|c|c|c|c|c|c|}
\hline $\begin{array}{l}\text { Instit } \\
\text { ute }\end{array}$ & A & B & C & D & $\mathbf{E}$ & $\begin{array}{c}\text { Mea } \\
\text { n } \\
\text { Scor } \\
\text { e }\end{array}$ & $\begin{array}{c}\text { Star } \\
\text { Rating } \\
\text { (Mean } \\
\text { / 20) }\end{array}$ \\
\hline Q1 & 50 & 75 & 100 & 100 & 75 & 80 & 4.00 \\
\hline Q2 & 50 & 0 & 25 & 100 & 100 & 55 & 2.75 \\
\hline Q3 & 75 & 75 & 75 & 100 & 75 & 80 & 4.00 \\
\hline $\begin{array}{c}\text { Summ } \\
\text { ary } \\
\text { Rating }\end{array}$ & & & & & & & 3.58 \\
\hline
\end{tabular}

Provider Mean Score for Question 1

$$
\begin{aligned}
& =\frac{50+75+100+75}{5} \\
& =80
\end{aligned}
$$

Provider Star Rating Question $1=\frac{80}{20}$

$=4$ Stars

Provider Summary Star Rating $=\frac{4+2.75+4}{3}=$ 3.58 Stars 


\section{RESULT}

\subsection{Home page}

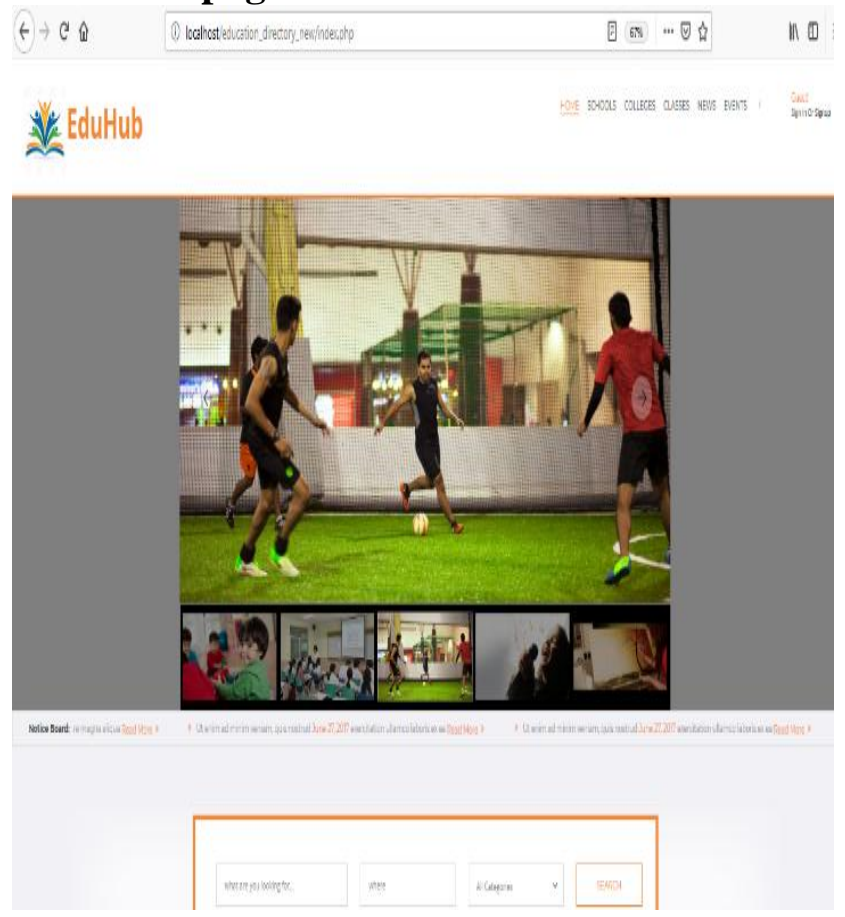

In this home page, some slider images be taken, also at top two options are given. One is Log In for those whose sign up is already completed and second is Sign Up to new user. Below the slider images there is institutes search block in which three sections are given such as what are you looking for, location, and categories colleges, school and classes.

\subsection{Sign Up Page}

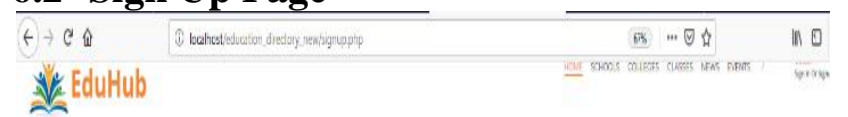
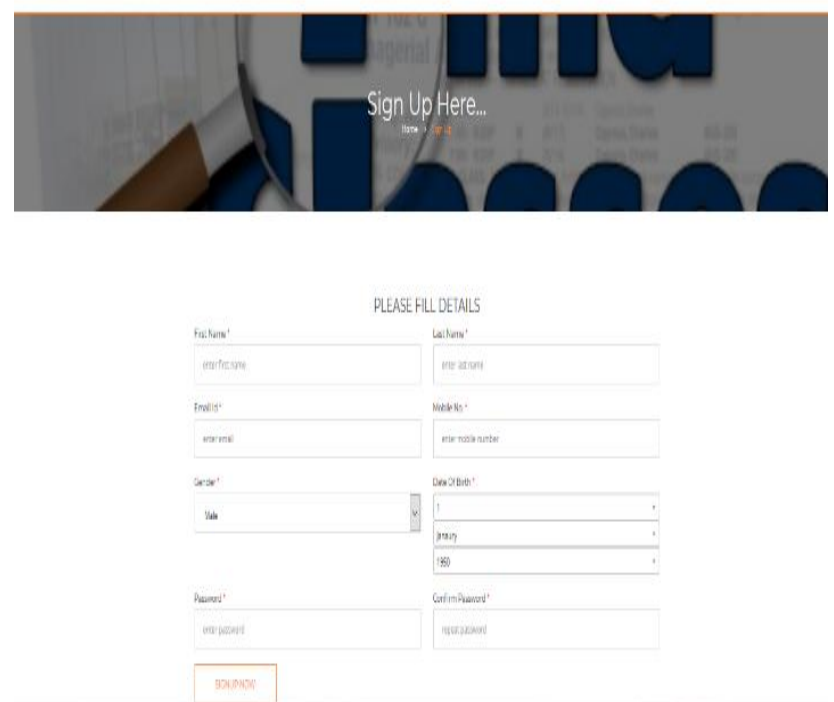

In sign up page, if a new user wants to add new institute or give reviews and that user has not created their login password then it is mandatory for user to sign up. For signing up, user should have to fill their details.

\subsection{After Login Page}

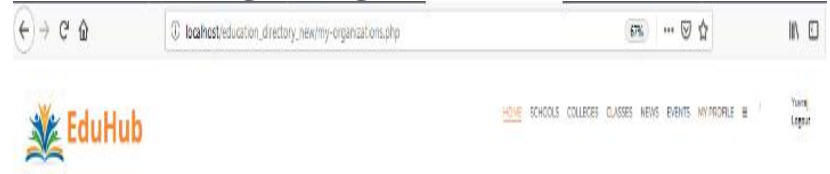

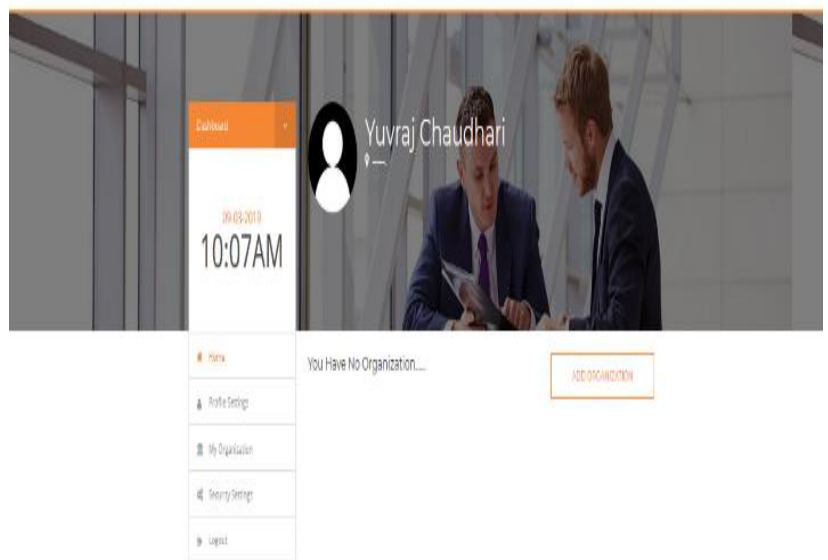

In this page, if user wants to add institute then he/she will have to first login and then can add institute. Then a dashboard will appear that include details like Profile settings, My organization and logout.

\subsection{Admin Panel}

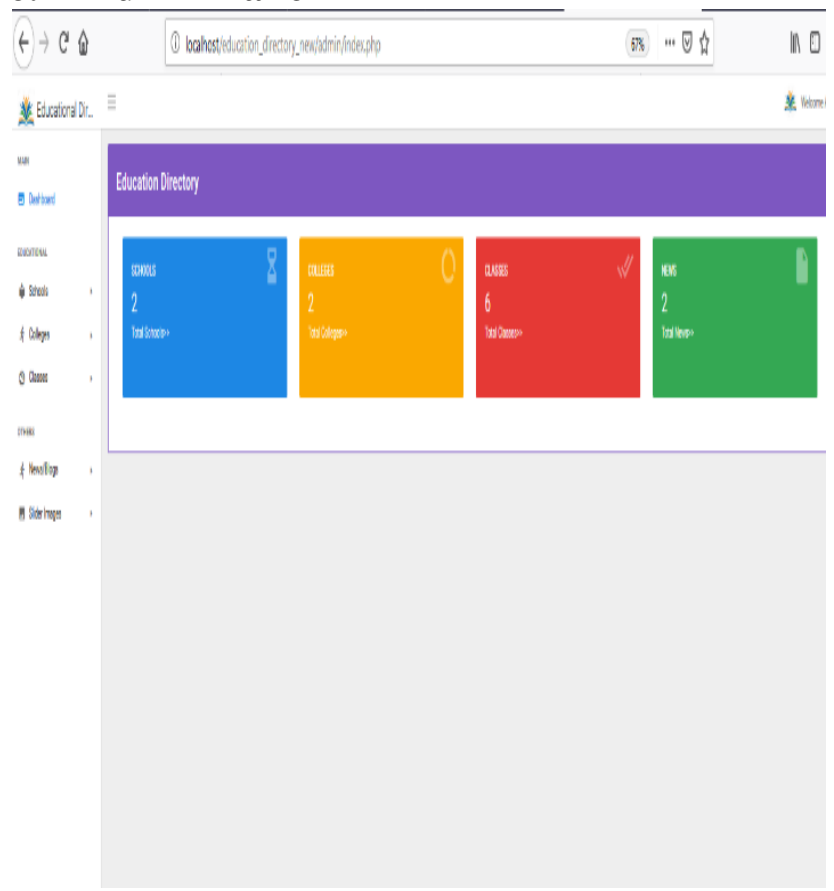

In Admin Panel, the dashboard gives the total counting of institutes which are categorize as schools, colleges and classes. In this panel, the appeared institutes were verified by admin. 


\section{CONCLUSION}

In this paper we proposed an approach for implementation of a web portal for online education directory. Web portal brings information together from diverse source in a uniform way. Portal is implemented through integration of services and applications that enables collaboration and communication among users in e-education system, realization of all institute activities, as well as adaptive functionalities. This paper introduced a web portal in which convenient looking out filtration of any kind of institute.

Future researches are directed toward improving adaptation mechanism and automation of adaptation process. We will bring all institutes from our country on web portal and provides e-education facilities.

\section{REFERENCES}

[1] The Commonwealth of Learning, "Best Practice in Education Portals" Research Document Prepared for the Commonwealth of Learning and Schoolnet Africa, October 2002.

[2] Pratibha S. Yalagi, Chaitrali S. Dangare "Design of An Academic Web Portal Providing E-Facilities" International Journal of Computer Science Engineering and Information Technology Research (IJCSEITR), Vol. 3, Issue 1, PP 85-90, Mar 2013.

[3] Ofoegbu E. O., Fayemiwo M. A., Omisore M. O., Olanrewaju P. O., "A Web Portal Architectural Design and Implementation for Private Universities in Nigeria",
International Journal of Scientific and Research Publications, Vol. 4, Issue 9, September 2014

[4] Anand Singh, Aishwary Shukla, Maulik Sharma, Rahul Yadav, Vidyadhari Singh, "Placement Test Web Portal", IOSR Journal of Computer Engineering (IOSR-JCE), PP 58-61, 2017

[5] Prof. Omkar. S. Vaidya, Mr. Tanmoy Bakshi, "Design of a Multifunctional Web Portal for College Departmental Activities", International Research Journal of Engineering and Technology (IRJET), Vol. 04 Issue: 05, May -2017

[6] Saurabh Walia, Satinderjit Kaur Gill, "Framework for Web Based Student Record Management System using PHP", International Journal of Computer Science and Mobile Computing, Vol. 3, Issue. 8, pp. 24-33, August 2014.

[7] Omkar Tiware, Prof. Kirti Rajadnya, Siddhesh Shinde, "College Activity Management System", International Research Journal of Engineering and Technology (IRJET), Vol. 05 Issue: 03, Mar-2018.

[8] Idogho O. Philipa, Akpado Kenneth, James Agajo, "Interactive Intranet Portal for effective Management in Tertiary Institution", International Journal of Advanced Computer Science and Applications (IJACSA), Vol. 2, No. 6, 2011

[9] Tejaswini Chavan, Deb Dutta, Michelle Gomez and Alvino Vaz," Online College Portal", International Journal of Current Engineering and Technology, Vol.5, No.1, Feb 2015.. 